\title{
Effect of Throwing Kinematics and Kinetics on Different Ranges of Long Toss in Youth Baseball Players ${ }^{+}$
}

\author{
Katsutoshi Nishino 1,*, Noriaki Yamamoto ${ }^{2}$, Masaei Tanaka ${ }^{1}$, Taisuke Ohishi ${ }^{2}$, Yasuo Tanaka ${ }^{2}$, \\ Naoto Okamura ${ }^{2}$, Hiroyuki Sekine ${ }^{2}$, Masaaki Arakawa ${ }^{1}$ and Go Omori ${ }^{3}$ \\ 1 Niigata Institute for Health and Sports Medicine, 67-12 Seigorou, Chuoh-ku, Niigata, 950-0933, Japan; \\ m.tanaka@ken-supo.jp (M.T.); m.arakawa@ken-supo.jp (M.A.) \\ 2 Niigata Rehabilitation Hospital, 761 Kizaki, Kita-ku, Niigata 950-3304, Japan; \\ nirehp.yamamoto@aiko.or.jp (N.Y.); taisukeohishi@gmail.com (T.O.); nirehp.pt@aiko.or.jp (Y.T.); \\ gakkan.okamura@gmail.com (N.O.); nirehp.pt@aiko.or.jp (H.S.) \\ 3 Department of Health and Sports, Niigata University of Health and Welfare, 1398 Shimami-cho, Kita-ku, \\ Niigata 950-3198, Japan; omori@nuhw.ac.jp \\ * Correspondence: k.nishino@ken-supo.jp; Tel.: +81-25-287-8806 \\ + Presented at the 13th conference of the International Sports Engineering Association, Online, \\ 22-26 June 2020.
}

Published: 15 June 2020

\begin{abstract}
Long-toss throwing is a baseball exercise that enhances the throwing performance of youth players. However, throwing kinematics and kinetics have not been fully investigated. This study aimed to analyze the effect of throwing kinematics and kinetics on different ranges of long toss in 22 youth players of the same age. The throwing motion was analyzed as the range of long toss was increased by $10 \mathrm{~m}$ each time until the ball did not directly reach the target. The twelve subjects who could throw long distances had a significantly larger physique and larger throwing kinematics and kinetics compared to the other 10 subjects who could not. No differences in the proximal force of the shoulder and elbow joints were observed between the two groups. These findings suggest that baseball coaches should set a suitable range of long toss for youth players according to the individual's physical growth and strength.
\end{abstract}

Keywords: baseball; youth player; long toss; throwing; kinematics; kinetics

\section{Introduction}

Long toss is a typical exercise program used among early teenage baseball players to learn baseball pitching mechanics and enhance their throwing performance. However, overuse throwing injury occurs frequently in youth players, with $18.3 \%$ and $35.2 \%$ experiencing pain in the shoulder and elbow, respectively [1]. Therefore, baseball coaches should take various measures to reduce the risk of overuse throwing injuries among youth players.

Although a previous study of baseball pitching suggested that youth pitchers who were taught proper pitching mechanics tended to have a reduced load on the shoulder and elbow joints [2], the load on the shoulder and elbow joints increased as the ball velocity increased [3]. The long toss which is one of baseball exercises has similar issues with pitching. For example, it has been speculated that the longer the range of long toss, the greater the difference in throwing kinematics and, hence, the greater the load on the shoulder and elbow joints. However, throwing kinematics and kinetics during long toss have not been fully investigated [4-7], especially among youth players. 
This study aimed to analyze the effect of throwing kinematics and kinetics on different ranges of long toss in youth baseball players. We hypothesized that the throwing kinematics and kinetics during long toss in these players would show a large difference even at the same age and would affect the maximum range of long toss.

\section{Materials and Methods}

\subsection{Subject}

Subjects were recruited from three different youth baseball teams in Japan. Inclusion criteria were as follows: (1) male, (2) sixth grader in elementary school (age 11-12 years), (3) $\geq 2$ years of experience playing baseball, and (4) healthy throwing arm with no injuries. A total of 22 subjects agreed to participate in this study.

This study was conducted according to the protocol approved by the Institutional Review Board of Niigata Institute for Health and Sports Medicine, Japan (approval No. 34). The objectives of the study were explained to the subjects, their parents, and team coaches; written consent was obtained from all of them prior to study participation.

\subsection{Data Acquisition}

Reflective markers were attached to the following parts of the subject's body: head, clavicle, sternum, 7th cervical spine, 10th thoracic spine, acromion, elbow joint (lateral and medial epicondyles), wrist joint (ulna and radius), 3rd metacarpal bone, iliac spines of the pelvis, lateral side of the knee joint, lateral side of the ankle joint, toe, and heel. In each trial, the subjects long tossed a ball from a release line toward a distant target in one forward step without a crow hop. After some warming up, the subjects started throwing at a $10 \mathrm{~m}$ range and then the range was increased by $10 \mathrm{~m}$ each time until the ball thrown did not directly reach the target (Figure 1a). A motion capture system with eight infrared cameras (VICON, Vicon Motion Systems Ltd., Yarnton, UK) was used to capture the throwing motion during the long-toss test at a sampling rate of $250 \mathrm{~Hz}$ (Figure 1b).

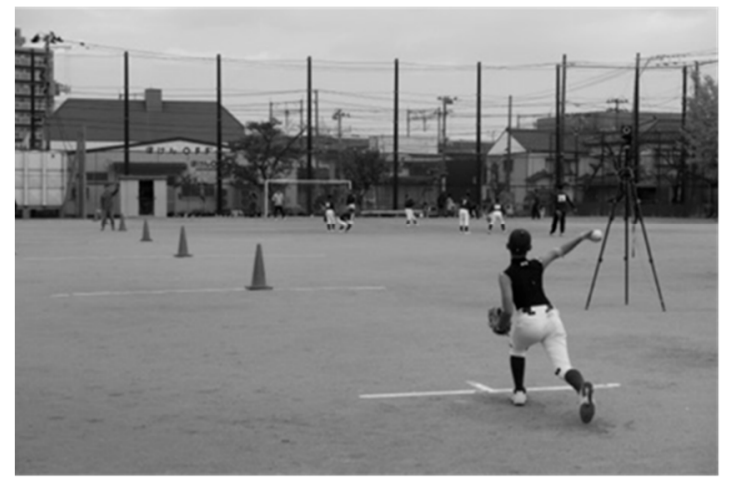

(a)

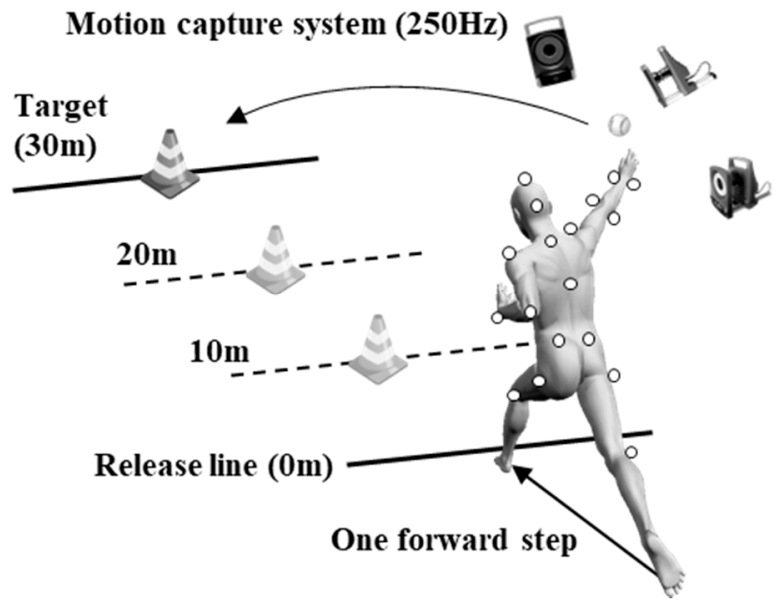

(b)

Figure 1. Test procedure. (a) Long-toss test, (b) Capture of throwing motion during test.

\subsection{Data Analysis}

Positional data from the reflective markers on the body during the long toss were smoothed by a fourth-order zero-lag Butterworth filter with a cut-off frequency of $20 \mathrm{~Hz}$. Four body segments of the throwing arm (thorax, upper arm, forearm, and hand) were constructed from the positions of the reflective markers; the center of gravity (COG) of each segment at a time $t, \boldsymbol{p}_{\text {seg }}(t)$, was estimated according to a previous study [8]. Three joint angles (shoulder, elbow, and wrist) were represented as Euler rotational angles. The throwing velocities of the elbow and wrist joints were obtained by a 
time differential of the joint center position. The shoulder internal rotation velocity was computed by a time differential of shoulder internal rotation.

The kinetics of the shoulder and elbow joints during long toss were calculated by inverse dynamics (Figure 2). The joint reaction forces on the proximal and distal edges of the segment were defined as $\boldsymbol{F}_{\text {prox }}(t)$ and $\boldsymbol{F}_{\text {dist }}(t)$, respectively. The mass of segment, $m_{\text {seg }}$, was obtained according to a previous study [8]. The $\boldsymbol{F}_{\text {prox }}(t)$ was estimated by Newton's motion equation,

$$
\boldsymbol{F}_{\text {prox }}(t)=m_{\text {seg }} \cdot \frac{d^{2}}{d t^{2}} \boldsymbol{p}_{\text {seg }}(t)-m_{\text {seg }} \cdot \boldsymbol{g}-\boldsymbol{F}_{\text {dist }}(t),
$$

where $\boldsymbol{g}$ is the acceleration due to gravity $\left(9.8 \mathrm{~m} / \mathrm{s}^{2}\right)$.

The joint moments on the proximal and distal sides of the segment were defined as $\boldsymbol{M}_{\text {prox }}(t)$ and $\boldsymbol{M}_{\text {dist }}(t)$, respectively. $\boldsymbol{M}_{\text {prox }}(t)$ was obtained by Eular's momentum equation,

$$
\boldsymbol{M}_{\text {prox }}(t)=\boldsymbol{I}_{\text {seg }} \cdot \frac{d}{d t} \boldsymbol{\omega}_{\text {seg }}(t)-\boldsymbol{M}_{\text {dist }}(t)-\boldsymbol{r}_{\text {dist }} \times \boldsymbol{F}_{\text {dist }}(t)-\boldsymbol{r}_{\text {prox }} \times \boldsymbol{F}_{\text {prox }}(t),
$$

where $\boldsymbol{r}_{\text {prox }}$ and $\boldsymbol{r}_{\text {dist }}$ are the position vectors from the COG to the proximal and distal edges of the segment, respectively. $\boldsymbol{\omega}_{\text {seg }}(t)$ denoted the angular velocity vector of the segment. The inertia moment of the segment, $\boldsymbol{I}_{\text {seg }}$, was estimated according to a previous study [8]. All the kinetic data were represented as the internal force and moment of the joint, and the following components of kinetic data were evaluated as the load on the shoulder and elbow joints: shoulder proximal force, elbow proximal forces, shoulder internal rotation moment, and elbow varus moment.

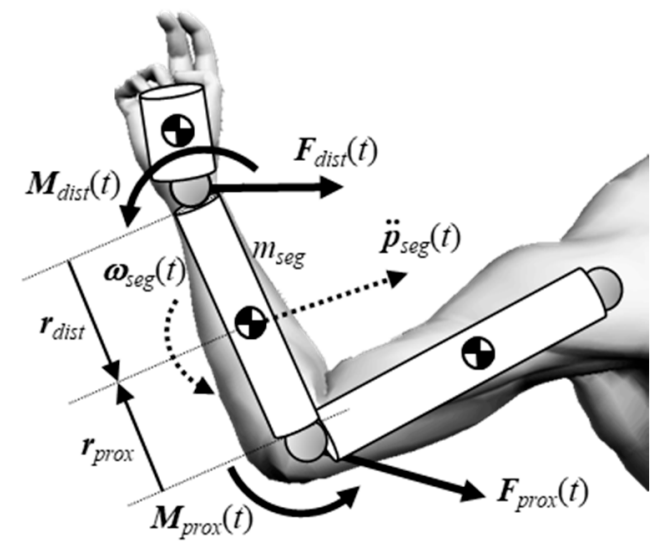

Figure 2. Joint reaction force and joint moment by inverse dynamics.

\subsection{Statistical Analysis}

The subjects who could throw long-range ( $\geq 40 \mathrm{~m}$ ) were classified as the L group. The remaining subjects were classified as the $\mathrm{S}$ group.

The throwing motion was divided into four phases: forward-step start, ground contact of the landing foot, maximum external rotation of the shoulder joint (MER), and ball release (BR). The kinematic and kinetic parameters were represented as their peak values during the long toss (from forward-step start to BR). The kinematic and kinetic values at each phase were also calculated.

Differences in the kinematic and kinetic parameters among the different ranges of long toss were evaluated by a one-way repeated measure analysis of variance with a post hoc analysis using Bonferroni's $t$ test. Differences in the kinematics and kinetics between the two groups were evaluated by a Student's t-test for each range. The statistical significance level (alpha) was set at .05.

\section{Results}

One subject could throw a maximum range of $50 \mathrm{~m}$. Eleven subjects threw a maximum range of $40 \mathrm{~m}$, and 10 subjects threw a maximum range of $30 \mathrm{~m}$. Twelve subjects were classified into the $\mathrm{L}$ group, and 10 were classified into the $S$ group (Table 1 ). The L group had a significantly higher height and weight compared to the $S$ group $(P<0.05)$. 
As the range of long toss increased, all the parameters except for the shoulder abduction at BR significantly increased in both groups (Tables 2 and 3).

The $L$ group had significantly higher throwing velocities of the arm and joint moment compared to the $\mathrm{S}$ group, regardless of range (Table 4 ). The joint reaction forces did not differ significantly between the two groups in ranges beyond $20 \mathrm{~m}$ (Table 4).

Table 1. Subjects' profiles.

\begin{tabular}{lccc}
\hline Parameter & L $(\boldsymbol{n}=\mathbf{1 2})$ & $\mathbf{S}(\boldsymbol{n}=\mathbf{1 0})$ & $\boldsymbol{P}$ \\
\hline Age $($ years old $)$ & $11.5 \pm 0.5$ & $11.6 \pm 0.5$ & .658 \\
\hline Height $(\mathrm{cm})$ & $151.1 \pm 6.2$ & $144.7 \pm 7.1$ & .035 \\
\hline Weight $(\mathrm{kg})$ & $42.3 \pm 5.4$ & $37.1 \pm 5.1$ & .034 \\
\hline Playing experience (years) & $4.5 \pm 1.4$ & $4.1 \pm 1.3$ & .505 \\
\hline
\end{tabular}

L: subjects who could throw long-range ( $\geq 40 \mathrm{~m})$; S: subjects who threw short-range $(<40 \mathrm{~m})$.

Table 2. Throwing kinematics and kinetics of subjects who could throw long-range: $n=12$.

\begin{tabular}{|c|c|c|c|c|c|c|c|}
\hline \multirow{2}{*}{ Parameter } & \multicolumn{4}{|c|}{ Range of Long Toss } & \multicolumn{3}{|c|}{$P$} \\
\hline & A: $10 \mathrm{~m}$ & B: $20 \mathrm{~m}$ & $\mathrm{C}: 30 \mathrm{~m}$ & $\mathrm{D}: 40 \mathrm{~m}$ & A vs. B & B vs. C & C vs. D \\
\hline $\begin{array}{l}\text { Elbow throwing } \\
\text { velocity }(\mathrm{km} / \mathrm{h})\end{array}$ & $25.4 \pm 3.1$ & $30.2 \pm 3.6$ & $32.2 \pm 2.6$ & $33.6 \pm 2.9$ & $<0.001$ & 0.045 & 0.121 \\
\hline $\begin{array}{l}\text { Wrist throwing } \\
\text { velocity }(\mathrm{km} / \mathrm{h})\end{array}$ & $33.2 \pm 3.0$ & $39.9 \pm 3.9$ & $42.9 \pm 2.5$ & $45.1 \pm 2.9$ & $<0.001$ & 0.008 & 0.023 \\
\hline $\begin{array}{l}\text { Shd abduction @BR } \\
\text { (deg) }\end{array}$ & $\begin{array}{c}90.4 \pm \\
10.5\end{array}$ & $\begin{array}{c}91.5 \pm \\
12.8\end{array}$ & $\begin{array}{c}90.6 \pm \\
13.6\end{array}$ & $\begin{array}{c}90.6 \pm \\
12.5\end{array}$ & 0.999 & 0.999 & 0.999 \\
\hline $\begin{array}{l}\text { Shd rotation @MER } \\
(\mathrm{deg})\end{array}$ & $\begin{array}{c}170.3 \pm \\
16.2 \\
\end{array}$ & $\begin{array}{c}176.6 \pm \\
14.8 \\
\end{array}$ & $\begin{array}{c}179.6 \pm \\
15.5 \\
\end{array}$ & $\begin{array}{c}182.2 \pm \\
17.3 \\
\end{array}$ & $<0.001$ & 0.048 & 0.135 \\
\hline $\begin{array}{l}\text { Elb flexion } @ B R \\
(\mathrm{deg})\end{array}$ & $30.1 \pm 8.2$ & $25.2 \pm 7.6$ & $22.8 \pm 6.9$ & $19.6 \pm 6.7$ & 0.002 & 0.119 & 0.003 \\
\hline $\begin{array}{l}\text { Shd int. rotation } \\
\text { velocity }(\mathrm{deg} / \mathrm{s})\end{array}$ & $\begin{array}{c}3344 \pm \\
695 \\
\end{array}$ & $\begin{array}{c}4226 \pm \\
700 \\
\end{array}$ & $\begin{array}{c}4699 \pm \\
670 \\
\end{array}$ & $\begin{array}{c}5157 \pm \\
668 \\
\end{array}$ & $<0.001$ & 0.054 & 0.024 \\
\hline $\begin{array}{l}\text { Shd proximal force } \\
\text { (N) }\end{array}$ & $\begin{array}{c}135.8 \pm \\
28.3 \\
\end{array}$ & $\begin{array}{c}193.1 \pm \\
38.9\end{array}$ & $\begin{array}{c}215.9 \pm \\
26.1 \\
\end{array}$ & $\begin{array}{c}238.7 \pm \\
39.4\end{array}$ & $<0.001$ & 0.055 & 0.071 \\
\hline $\begin{array}{l}\text { Elb proximal force } \\
(\mathrm{N})\end{array}$ & $\begin{array}{c}124.9 \pm \\
25.6\end{array}$ & $\begin{array}{c}166.4 \pm \\
32.1 \\
\end{array}$ & $\begin{array}{c}182.2 \pm \\
24.6\end{array}$ & $\begin{array}{c}196.9 \pm \\
34.5 \\
\end{array}$ & $<0.001$ & 0.017 & 0.042 \\
\hline $\begin{array}{l}\text { Shd int. rotation } \\
\text { moment }(\mathrm{Nm})\end{array}$ & $\begin{array}{c}11.28 \pm \\
2.15\end{array}$ & $\begin{array}{c}14.55 \pm \\
2.96\end{array}$ & $\begin{array}{c}15.80 \pm \\
2.89 \\
\end{array}$ & $\begin{array}{c}17.08 \pm \\
3.62 \\
\end{array}$ & $<0.001$ & 0.006 & 0.027 \\
\hline $\begin{array}{l}\text { Elb varus moment } \\
(\mathrm{Nm})\end{array}$ & $\begin{array}{c}11.32 \pm \\
2.28 \\
\end{array}$ & $\begin{array}{c}14.58 \pm \\
3.03 \\
\end{array}$ & $\begin{array}{c}15.88 \pm \\
3.17 \\
\end{array}$ & $\begin{array}{c}17.25 \pm \\
3.84 \\
\end{array}$ & $<0.001$ & 0.048 & 0.036 \\
\hline
\end{tabular}

P: $P$ value; Shd: shoulder; Elb: elbow; MER: maximum external rotation; BR: ball release.

Table 3. Throwing kinematics and kinetics of subjects who threw short-range: $n=10$.

\begin{tabular}{lccccc}
\hline \multirow{2}{*}{ Parameter } & \multicolumn{3}{c}{ Range of Long Toss } & \multicolumn{1}{c}{$\boldsymbol{P}$} \\
\cline { 2 - 6 } & A: $\mathbf{1 0 ~} \mathbf{~}$ & B: $\mathbf{2 0 ~} \mathbf{~ m}$ & C: $\mathbf{3 0 ~ m}$ & A vs. B & B vs. C \\
\hline Elbow throwing velocity $(\mathrm{km} / \mathrm{h})$ & $21.9 \pm 2.1$ & $27.8 \pm 1.6$ & $29.5 \pm 1.4$ & $<0.001$ & 0.012 \\
Wrist throwing velocity $(\mathrm{km} / \mathrm{h})$ & $29.0 \pm 2.8$ & $37.6 \pm 3.1$ & $40.2 \pm 2.7$ & $<0.001$ & 0.004 \\
Shd abduction @BR $(\mathrm{deg})$ & $97.1 \pm 7.9$ & $94.4 \pm 6.8$ & $93.9 \pm 9.6$ & 0.445 & 0.999 \\
Shd rotation @MER $(\mathrm{deg})$ & $170.8 \pm 8.3$ & $181.1 \pm 12.0$ & $182.6 \pm 9.1$ & 0.002 & 0.729 \\
Elb flexion @BR (deg) & $30.1 \pm 9.1$ & $25.9 \pm 10.4$ & $22.5 \pm 9.9$ & 0.032 & 0.020 \\
Shd int. rotation velocity $(\mathrm{deg} / \mathrm{s})$ & $2923 \pm 503$ & $3859 \pm 648$ & $4338 \pm 793$ & 0.001 & 0.004 \\
Shd proximal force $(\mathrm{N})$ & $108.8 \pm 18.2$ & $166.9 \pm 31.3$ & $193.5 \pm 40.0$ & $<0.001$ & 0.002 \\
Elb proximal force $(\mathrm{N})$ & $103.0 \pm 19.1$ & $145.4 \pm 26.7$ & $162.5 \pm 31.8$ & $<0.001$ & 0.001 \\
Shd int. rotation moment $(\mathrm{Nm})$ & $7.60 \pm 1.77$ & $10.43 \pm 2.14$ & $11.34 \pm 2.28$ & $<0.001$ & 0.002 \\
Elb varus moment $(\mathrm{Nm})$ & $7.71 \pm 1.97$ & $10.50 \pm 2.68$ & $11.57 \pm 2.81$ & $<0.001$ & $<0.001$ \\
\hline
\end{tabular}

$P: P$ value; Shd: shoulder; Elb: elbow; MER: maximum external rotation; BR: ball release. 
Table 4. Difference in throwing between the two groups in each range of long toss.

\begin{tabular}{|c|c|c|c|c|c|c|c|}
\hline \multirow{2}{*}{ Parameter } & \multirow{2}{*}{ Group } & \multicolumn{6}{|c|}{ Range of Long Toss } \\
\hline & & $10 \mathrm{~m}$ & $P$ & $20 \mathrm{~m}$ & $P$ & $30 \mathrm{~m}$ & $P$ \\
\hline \multirow{2}{*}{$\begin{array}{l}\text { Elb throwing velocity } \\
(\mathrm{km} / \mathrm{h})\end{array}$} & $\mathrm{L}$ & $25.4 \pm 3.1$ & \multirow{2}{*}{0.006} & $30.2 \pm 3.6$ & \multirow{2}{*}{0.060} & $32.2 \pm 2.6$ & \multirow{2}{*}{0.008} \\
\hline & $S$ & $21.9 \pm 2.1$ & & $27.8 \pm 1.6$ & & $29.5 \pm 1.4$ & \\
\hline \multirow{2}{*}{$\begin{array}{l}\text { Wrt throwing velocity } \\
(\mathrm{km} / \mathrm{h})\end{array}$} & $\mathrm{L}$ & $33.2 \pm 3.0$ & \multirow{2}{*}{0.003} & $39.9 \pm 3.9$ & \multirow{2}{*}{0.142} & $42.9 \pm 2.5$ & \multirow{2}{*}{0.028} \\
\hline & $S$ & $29.0 \pm 2.8$ & & $37.6 \pm 3.1$ & & $40.2 \pm 2.7$ & \\
\hline \multirow{2}{*}{$\begin{array}{l}\text { Shd abduction @BR } \\
\text { (deg) }\end{array}$} & $\mathrm{L}$ & $90.4 \pm 10.5$ & \multirow{2}{*}{0.111} & $91.5 \pm 12.8$ & \multirow{2}{*}{0.519} & $90.6 \pm 13.6$ & \multirow{2}{*}{0.531} \\
\hline & $S$ & $97.1 \pm 7.9$ & & $94.4 \pm 6.8$ & & $93.9 \pm 9.6$ & \\
\hline \multirow{2}{*}{$\begin{array}{l}\text { Shd rotation @MER } \\
\text { (deg) }\end{array}$} & $\mathrm{L}$ & $170.3 \pm 16.2$ & \multirow{2}{*}{0.927} & $176.6 \pm 14.8$ & \multirow{2}{*}{0.452} & $179.6 \pm 15.5$ & \multirow{2}{*}{0.596} \\
\hline & $S$ & $170.8 \pm 8.3$ & & $181.1 \pm 12.0$ & & $182.6 \pm 9.1$ & \\
\hline \multirow{2}{*}{ Elb flexion @BR (deg) } & $\mathrm{L}$ & $30.1 \pm 8.2$ & \multirow{2}{*}{0.988} & $25.2 \pm 7.6$ & \multirow{2}{*}{0.858} & $22.8 \pm 6.9$ & \multirow{2}{*}{0.935} \\
\hline & $S$ & $30.1 \pm 9.1$ & & $25.9 \pm 10.4$ & & $22.5 \pm 9.9$ & \\
\hline \multirow{2}{*}{$\begin{array}{l}\text { Shd internal rotation } \\
\text { velocity }(\mathrm{deg} / \mathrm{s})\end{array}$} & $\mathrm{L}$ & $3344 \pm 695$ & \multirow{2}{*}{0.126} & $4226 \pm 700$ & \multirow{2}{*}{0.221} & $4699 \pm 670$ & \multirow{2}{*}{0.260} \\
\hline & $S$ & $2923 \pm 503$ & & $3859 \pm 648$ & & $4338 \pm 793$ & \\
\hline \multirow{2}{*}{ Shd proximal force $(\mathrm{N})$} & $\mathrm{L}$ & $135.8 \pm 28.3$ & \multirow{2}{*}{0.017} & $193.1 \pm 38.9$ & \multirow{2}{*}{0.101} & $215.9 \pm 26.1$ & \multirow{2}{*}{0.130} \\
\hline & $S$ & $108.8 \pm 18.2$ & & $166.9 \pm 31.3$ & & $193.5 \pm 40.0$ & \\
\hline \multirow{2}{*}{ Elb proximal force $(\mathrm{N})$} & $\mathrm{L}$ & $124.9 \pm 25.6$ & \multirow{2}{*}{0.037} & $166.4 \pm 32.1$ & \multirow{2}{*}{0.115} & $182.2 \pm 24.6$ & 0118 \\
\hline & $S$ & $103.0 \pm 19.1$ & & $145.4 \pm 26.7$ & & $162.5 \pm 31.8$ & 0.118 \\
\hline Shd internal rotation & $\mathrm{L}$ & $11.28 \pm 2.15$ & & $14.55 \pm 2.96$ & בחת ח & $15.80 \pm 2.89$ & 0001 \\
\hline moment $(\mathrm{Nm})$ & $S$ & $7.60 \pm 1.77$ & $<0.001$ & $10.43 \pm 2.14$ & 0.002 & $11.34 \pm 2.28$ & 0.001 \\
\hline & $\mathrm{L}$ & $11.32 \pm 2.28$ & $<0001$ & $14.58 \pm 3.03$ & 0.004 & $15.88 \pm 3.17$ & 0003 \\
\hline EID varus moment (Nm) & $S$ & $7.71 \pm 1.97$ & & $10.50 \pm 2.68$ & & $11.57 \pm 2.81$ & 0.000 \\
\hline
\end{tabular}

L: subjects who could throw long-range $(\geq 40 \mathrm{~m})$; $S$ : subjects who threw short-range $(<40 \mathrm{~m}) ; P$ : $P$ value; Shd: shoulder; Elb: elbow; Wrt: wrist; MER: maximum external rotation of shoulder joint; BR: ball release.

\section{Discussion}

In this study, the throwing arm velocity and shoulder internal rotation velocity increased with increasing long-toss range. The shoulder external rotation angle was larger at MER immediately before the arm acceleration phase, while the elbow flexion angle at BR was smaller. The shoulder moment and elbow joint moment increased as the range of long toss increased. These results were consistent with previous reports on long toss in high school and collegiate subjects [4,5].

On the other hand, no difference was observed in the shoulder abduction among the different ranges. A previous study reported that the arm angle with respect to the ground (i.e., arm slot) increased with an increasing range of long toss [5]. This may suggest that the increase in arm slot was achieved by the compensatory motion of other segments, such as the lateral tilts of thorax and pelvis.

Subjects in the L group had a significantly larger physique and also showed significantly larger throwing kinematics and kinetics compared to those in the $S$ group, regardless of the range of long toss. A previous study suggested that increases in kinematics and kinetics during pitching might be associated with muscle mass and arm length [3]. Thus, the observed increases in kinematics and kinetics might be explained by differences in the subjects' physical growth and muscular strength regardless of the range of long toss, suggesting that the throwing performance of youth players might be affected by both physical growth and strength.

There were no differences in the proximal force of shoulder and elbow joints between the two groups. As this force corresponds to the compression load in the axial direction of the joints, subjects in the $S$ group, who had a smaller physique, might have received the same level of compression load as those in the $L$ group. Therefore, the risk of throwing injuries might be higher for the $S$ group than the $\mathrm{L}$ group, even if the range of long toss was the same level.

In order to increase the range of long toss, enhancing the motor function of upper body as well as the muscular strength around the shoulder and elbow for enduring the shoulder and elbow joint loads caused by long-toss throwing may be important, although having a large physique is certainly essential. However, since early teenage players differ in physical strength even the same age and are in the early stage of bony growth, limiting the range of long toss to reduce loads might be more 
suitable than performing strength training to endure loads. The target range of long toss has been established based on the age and ball velocity of youth players [7]. However, our findings suggest the need for baseball coaches to set a suitable range of long toss for youth players according to the individual's physical growth and strength.

There are some limitations to this study. We were unable to clarify the muscular strength and physical ability and ball velocity of our subjects, which might have been directly related to increases in throwing kinematics and kinetics. In addition, the kinematics and kinetics of segments other than the throwing arm could not be analyzed, because throwing during long toss is a whole-body motion. These issues should be addressed in future studies in order to develop a safe and effective long-toss program for youth players.

\section{Conclusions}

This study aimed to analyze the effect of throwing kinematics and kinetics on different ranges of long toss in 22 youth players of the same age.

The shoulder moment and elbow joint moment during long toss increased as the range of long toss increased. The subjects who could throw long-range had a significantly larger physique and also showed significantly larger throwing kinematics and kinetics compared to those who threw shortrange. The risk of overuse throwing injuries might be higher for the subjects who threw short-range than for those who could throw long-range.

These findings suggested that baseball coaches should set a suitable range of long toss for youth players according to the individual's physical growth and strength.

Acknowledgments: This study was financially and technically supported by MIZUNO Corporation, Japan.

Conflicts of Interest: The authors declare no conflict of interest. The funding sponsors had no role in the design of the study; in the collection, analyses, or interpretation of data; in the writing of the manuscript, and in the decision to publish the results.

\section{References}

1. Matsuura, T.; Iwame, T.; Suzue, N.; Arisawa, K.; Sairyo, K. Risk factors for shoulder and elbow pain in youth baseball players. Phys. Sportsmed. 2017, 45, 140-144.

2. Davis, J.T.; Limpisvasti, O.; Fluhme, D.; Mohr, K.J.; Yocum, L.A.; Elattrache, N.S.; Jobe, F.W. The effect of pitching biomechanics on the upper extremity in youth and adolescent baseball pitchers. Am. J. Sports Med. 2009, 37, 1484-1491.

3. Fleisig, G.S.; Barrentine, S.W.; Zheng, N.; Escamilla, R.F.; Andrews, J.R. Kinematic and kinetic comparison of baseball pitching among various levels of development. J. Biomech. 1999, 32, 1371-1375.

4. Fleisig, G.S.; Bolt, B.; Fortenbaugh, D.; Wilk, K.E.; Andrews, J.R. Biomechanical comparison of baseball pitching and long-toss: Implications for training and rehabilitation. J. Orthop. Sports Phys. Ther. 2011, 41, 296-303.

5. Dowling, B.; McNally, M.P.; Laughlin, W.A.; Onate, J.A. Changes in throwing arm mechanics at increased throwing distances during structured long-toss. Am. J. Sports Med. 2018, 46, 3002-3006.

6. Melugin, H.P.; Larson, D.R.; Fleisig, G.S.; Conte, S.; Fealy, S.A.; Dines, J.S.; D’ Angelo, J.; Camp, C.L. Baseball Pitchers' Perceived Effort Does Not Match Actual Measured Effort During a Structured Long-Toss Throwing Program. Am. J. Sports Med. 2019, 47, 1949-1954.

7. Axe, M.J.; Snyder-Mackler, L.; Konin, J.G.; Strube, M.J. Development of a distance-based interval throwing program for little league-aged athletes. Am. J. Sports Med. 1996, 24, 594-602.

8. Ae, M. Body partial inertia coefficient of Japanese athletes and infants. Jpn. J. Sports. Sci. 1996, 15, $155-162$. (In Japanese)

(C) 2020 by the authors. Licensee MDPI, Basel, Switzerland. This article is an open access article distributed under the terms and conditions of the Creative Commons Attribution (CC BY) license (http://creativecommons.org/licenses/by/4.0/). 